\title{
The Outcome of Laparoscopic Ovarian Drilling in Patients with Clomiphene-resistant Polycystic Ovarian Syndrome in Ogbmoso, Nigeria: A Prospective Evaluation
}

\author{
Akintunde O Fehintola ${ }^{1}$, Olufemi T Awotunde ${ }^{2}$, Olumuyiwa A Ogunlaja ${ }^{3}$, Samuel E Akinola ${ }^{4}$, Sunday A Oladeji ${ }^{5}$, \\ Olurotimi I Aaron ${ }^{6}$, Funmito O Fehintola ${ }^{7}$
}

\begin{abstract}
Background: Polycystic ovary syndrome (PCOS) is commonly encountered in women with anovulatory infertility. The surgical ovarian drilling procedure aims to restore spontaneous ovulatory cycles. This function is similar to the goal of clomiphene citrate and/or metformin.

Objective: We conducted this study to determine the outcome of laparoscopic ovarian drilling (LOD) among patients who presented with clomiphene-resistant PCOS.

Materials and methods: The study was prospective in design. We studied 43 patients with clomiphene-resistant PCOS who had laparoscopic ovarian drilling (LOD) using monopolar diathermy at the Bowen University Teaching Hospital, Ogbomoso. The study took place between January 2014 and June 2016. Clinical data recorded at different intervals of follow-up included the menstrual pattern and reproductive history. Results: We successfully performed laparoscopic ovarian drilling without any complication. Four (9.3\%) of the patients were lost to follow-up. Thirty (76.9\%) of the remaining 39 patients resumed regular menstrual cycles with spontaneous ovulation, while 23 (59.1\%) patients achieved spontaneous pregnancy within 6 and 18 months following LOD. No record of multiple pregnancies. Factors associated with failed LOD treatment included obesity and a long duration of infertility.

Conclusion: LOD is a feasible and effective first-line treatment option in patients with clomiphene-resistant PCOS in sub-Saharan Africa. Emphasis should be on weight reduction with early application of LOD to treat patients with clomiphene-resistant PCOS. This will reduce the time to achieve pregnancy and the need for gonadotropins to induce ovulation.

Keywords: Clomiphene-resistant polycystic ovary syndrome, Laparoscopic ovarian drilling, Treatment outcome.

World Journal of Laparoscopic Surgery (2020): 10.5005/jp-journals-10033-1418
\end{abstract}

\section{INTRODUCTION}

The most common endocrinopathy in women within the reproductive-age group is polycystic ovary syndrome (PCOS). It affects about $6-8 \%$ of this age-group. ${ }^{1-4}$ PCOS forms a spectrum of disorders from a heterogeneous collection of signs and symptoms. Its presentation may be mild in some, while reports show severe disturbance of reproductive, endocrine, and metabolic functions in others. ${ }^{5}$ The prevalence of PCOS varies among races and ethnicities with a range between 5 and $10 \%^{3}$

Previous data reported the highest prevalence rate of $52 \%$ among the South Asian immigrants in Britain, of whom $49.1 \%$ had menstrual irregularity. ${ }^{2}$ About $10 \%$ of the diagnosis of PCOS is made during gynecologic visits. ${ }^{2}$ Approximately $30-75 \%$ are obese, while $50 \%$ of patients have hirsutism ${ }^{3}$

In Nigeria, Ugwu et al. ${ }^{1}$ and Omokanye et al. ${ }^{4}$ reported prevalence rates of $18.1 \%$ and $31 \%$, respectively. In their series, the majority of the patients presented with infertility and oligomenorrhea. ${ }^{2}$ PCOS is responsible for about $75 \%$ of anovulatory infertility. ${ }^{6}$

PCOS predisposes women to diabetes mellitus, endometrial carcinoma, and cardiovascular disease..$^{7-9}$

The exact pathophysiology in PCOS is unknown. However, a genetic component is likely, since the condition tends to run in families. Also, the pattern of inheritance is X-linked dominance. ${ }^{10}$ Furthermore, studies have shown the occurrence of PCOS in approximately $50 \%$ of first-degree relatives. ${ }^{11}$ We can make a presumptive diagnosis of
${ }^{1}$ Department of Obstetrics and Gynaecology, Faculty of Clinical Sciences, Obafemi Awolowo University, Ile-Ife, Osun, Nigeria

${ }^{2-5}$ Department of Obstetrics and Gynaecology, Bowen University Teaching Hospital, Ogbomoso, Oyo, Nigeria

${ }^{6}$ Department of Anaesthesia, Faculty of Clinical Sciences, Obafemi Awolowo University, Ile-Ife, Osun, Nigeria

${ }^{7}$ Community Health Department, Faculty of Clinical Sciences, Obafemi Awolowo University, Ile-Ife, Osun, Nigeria

Corresponding Author: Akintunde O Fehintola, Department of Obstetrics and Gynaecology, Faculty of Clinical Sciences, Obafemi Awolowo University, Ile-Ife, Osun, Nigeria, Phone: +2348037998247, e-mail: akintunds@yahoo.com

How to cite this article: Fehintola AO, Awotunde OT, Ogunlaja OA, et al. The Outcome of Laparoscopic Ovarian Drilling in Patients with Clomiphene-resistant Polycystic Ovarian Syndrome in Ogbmoso, Nigeria: A Prospective Evaluation. World J Lap Surg 2020;13(3):101-107. Source of support: Nil

Conflict of interest: None

PCOS based on the history and examination findings. According to an international consensus, the syndrome can be diagnosed using the "Rotterdam criteria (presence of at least two of the following conditions): Oligomenorrhea or amenorrhea, hyperandrogenism, and polycystic ovaries on ultrasound. Researchers defined the

(O) The Author(s). 2020 Open Access This article is distributed under the terms of the Creative Commons Attribution 4.0 International License (https://creativecommons. org/licenses/by-nc/4.0/), which permits unrestricted use, distribution, and non-commercial reproduction in any medium, provided you give appropriate credit to the original author(s) and the source, provide a link to the Creative Commons license, and indicate if changes were made. The Creative Commons Public Domain Dedication waiver (http://creativecommons.org/publicdomain/zero/1.0/) applies to the data made available in this article, unless otherwise stated. 
morphology of polycystic ovaries as an ovary with 12 or more follicles measuring 2-9 $\mathrm{mm}$ in diameter and increased ovarian volume $(>10$ $\mathrm{cm}^{3}$ ) on transvaginal ultrasound (TVS)". ${ }^{12}$

The goals of the "symptom-oriented" PCOS management are to restore normal menstruation, ovulatory cycles, and fertility and prevent endometrial hyperplasia/cancer. It also involves the treatment of acne and infertility. Clinicians achieved ovulation induction in women with PCOS using various means in the past. ${ }^{7}$ The first-choice treatment presently in PCOS women is administration of clomiphene citrate (CC). ${ }^{7,8}$ We termed those who fail to ovulate with a maximum dose of clomiphene citrate (i.e., a daily dose of $150 \mathrm{mg}$ ) "Clomiphene Citrate Resistant (CCR)".13 Clomiphene citrate is successful in $80 \%$ of cases. The remaining $20 \%$ of patients who did not ovulate this drug are declared CCR. ${ }^{14}$

The use of gonadotropins and metformin and ovarian drilling are the treatment modalities for those with CCR. ${ }^{13}$

Gjonnaess first described LOD in $1984 .^{15}$ The introduction of this procedure reawakened interest in the surgical management of patients with CCR. This procedure involves the use of cautery or laser vaporization to create multiple perforations in the ovary. Previous data reported an increase in spontaneous ovulation and conception rates following LOD, along with improved responsiveness to subsequent medical therapy. ${ }^{15-17}$ Clinicians can do LOD as an outpatient procedure with less trauma and fewer postoperative adhesions. Conversely, although useful, gonadotropins expose the patients to a series of complications, such as multiple pregnancy and hyperstimulation. Furthermore, gonadotropins are expensive, and they require repeated doses and intensive monitoring. ${ }^{13}$

This study aimed at evaluating patients' characteristics as well as the results of LOD in patients with CCR polycystic ovarian syndrome in our center.

\section{Materials and Methods}

\section{Study Setting}

The study is prospective in design. We studied patients who had LOD at the gynecological endoscopy unit of the Obstetrics and Gynaecology Department, Bowen University Teaching Hospital, Ogbomoso, between January 01, 2014, and June 30, 2016. The center started gynecological endoscopy procedures in 2007 though mainly diagnostic. Operative procedures began in 2013.

\section{Inclusion and Exclusion Criteria}

We recruited patients with PCOS diagnosis based on the Rotterdam criteria $^{12}$ who have had up to a daily dose of $150 \mathrm{mg}$ clomiphene citrate without evidence of ovulation. We excluded those with absolute contraindication for laparoscopy. We also excluded patients with tubal pathology, severe endometriosis, severe male factor, and those who refuse LOD as a treatment modality.

\section{Methods}

We obtained sociodemographic data and other important information from the patient at the presentation. Information on the patient's level of education and the husband's occupation was also collected to group them into different social classes (i.e., socioeconomic classes 1 to 5). ${ }^{18}$ We further regroup the patients as upper, middle, and lower classes. We group classes 1 and 2 as upper social class, class 3 as a middle social class, while classes 4 and 5 were grouped as a lower social class to aid data analysis.

Investigation results, including transvaginal ultrasound (TVS) results, hormonal profile results (before and after LOD), body mass index (BMI), and the number of perforations per ovary during the procedure, were recorded in a proforma. Patients were followed up on a clinic basis and on the phone to get information on the resumption of menses, ovulation, and pregnancy. We confirmed ovulation with the ovulation test kit (Predict ${ }^{\circledR}$ ), day 12 to 14 follicular TVS study, and pregnancy after the procedure. We carried out data analysis with Statistical Package for Social Sciences (SPSS) version 20. A $p$ value of $<0.05$ was considered statistically significant.

\section{Definition of Term}

- Failed LOD; failure to resume regular menses with ovulation within 6-8 weeks following LOD.

- Clomiphene citrate-resistant PCOS; PCOS patients who failed to ovulate with $150 \mathrm{mg} /$ day dose of clomiphene citrate

\section{Outcome Variables}

Primary outcome variables include the resumption of menses with spontaneous ovulation and clinical pregnancy rates. We define clinical pregnancy as the presence of fetal cardiac activity on ultrasound. We define the clinical pregnancy rate as the percentage of patients with clinical pregnancy to the total number of participants at the end of the study. Other outcome measures included were live birth rate, miscarriage rate, multiple pregnancies, and OHSS rates.

\section{Procedure}

We obtained informed consent for LOD. After general anesthesia and skin preparation, we use the Veress needle to create pneumoperitoneum. With the assistant lifting the anterior abdominal wall, the surgeon inserted the needle through a stab incision in the umbilicus's inferior crease in the mid-line. We perform Veress needle insertion with the patient in the supine position. After this, the surgeon then places a 10-mm infra-umbilical (primary) port on the infraumbilical crease through a transverse incision. We also place two 5-mm lateral (secondary) ports in the right and left iliac fossae lateral to inferior epigastric vessels using the baseball diamond concept. The surgeon then inserts a 0-degree $10 \mathrm{~mm}$ telescope through the primary port and carries diagnostic laparoscopy with chromopertubation for tubal patency.

The surgeon then lifts the ovaries out of the ovarian fossa with an irrigation cannula inserted through the ipsilateral secondary ports. The cannula is wedged against the cervicouterine junction, giving a robust platform for drilling. We use a uterine manipulator to manipulate the uterus. The monopolar needle is then introduced from the contralateral secondary port and approaches the ovaries at right angles. We usually carry out 4-10 drills on each ovary based on the size of the ovary. We then carried out suction irrigation of the ovaries and peritoneal lavage using normal saline after the drill. The surgeon carries out irrigation to cool the ovaries and clear the pelvis of any blood clots and debris. After the procedure, the assistant removes the hand instruments and lets out pneumoperitoneum through the secondary ports. We remove these ports under the vision, followed by the laparoscope, and the $10-\mathrm{mm}$ trocar. The surgeon then closes the port wounds with subcuticular suturing using Vicryl 2/0.

\section{Treatment Protocol}

Research assistants fill the forms as part of the postoperative instructions for a repeat hormonal profile, especially for those who resume menses before their follow-up visits. A repeat Day 
2/3 FSH and LH, and Day 21 serum progesterone assay were done in patients with spontaneous menses post-LOD to assess for ovulation. Subsequent ovulation monitoring was done by either follicular tracking with TVS or the use of ovulation prediction kits from day 10 to 16 of the cycle. Patients who resumed spontaneous ovulation were observed for 6 months for conception to occur while on ovulation monitoring and timed intercourse (TI). After that, we subjected to either superovulation induction (SI) with timed intercourse ( $\mathrm{TI}$ ) or intrauterine insemination (IUI) on case-to-case basis. We offered patients who failed to conceive by these methods IVF. Patients who failed to ovulate following LOD will use other forms of second-line management of PCOS.

\section{Ethical Consideration}

We obtained ethical clearance for this study from the Bowen University Teaching Hospital's ethical review board, Ogbomoso. During data collection, we informed the individual patient about the purpose of the study, confidentiality, and the right not to participate or withdraw at any time without affecting their health or other services. We obtained written consent from each of the participants before the commencement of the study.

\section{Results}

We analyzed the patients' characteristics, hormonal profile, and the outcome of 43 eligible patients. Of the 430 patients who had infertility consultation at our facility, we diagnosed 80 (18.6\%) as a PCOS case. Forty-three (53.8\%) patients with clomiphene citrateresistant PCOS underwent LOD. We followed the patients up for an average duration of $11.2 \pm 6.3$ months (range 9-36 months), during which we lost four (9.3\%) patients to follow-up. The patients aged $21-43$ years with a mean age of $29.5 \pm 4.8$ years. Thirty $(69.8 \%)$ had primary infertility, 39 (90.7\%) were nulligravida, while 28 (65\%) belonged to low social class. The duration of infertility ranged from 1 to 18 years $(6.5 \pm 3.7)$. We recorded irregular cycles in $40(93 \%)$ patients, while $28(65.1 \%)$ had altered LH-FSH ratio ( $>2.0)$. The Body Mass Index (BMI) ranged from 24.3 to $39.7 \mathrm{~kg} / \mathrm{m}^{2}(26.3 \pm 8.5)$. The number of drills per ovary ranged from 4 to $10(6.5 \pm 2.7)$.

Thirty (76.9\%) of the remaining 39 patients with irregular cycles resumed regular menses with spontaneous ovulation with a mean duration of $5.2 \pm 2.6$ days and $3.4 \pm 2.3$ weeks, respectively. Most of those who resumed regular menses (66.7\%) did so within 4 to 6 days post-LOD. Twenty-three (59\%) patients had spontaneous conception (mean time of conception post drilling was $4.8 \pm 1.6$ months). Four patients (10.3\%) of 39 had an early first-trimester miscarriage and 19 (48.7\%) successful delivery. There was no record of complication of laparoscopy, multiple pregnancies, or ovarian hyperstimulation syndrome (OHSS).

There was a significant association between failed LOD and maternal age above 35years $\left(\chi^{2}=10.063, p\right.$ value $\left.=0.004\right), \geq 5$ years of infertility $\left(\chi^{2}=4.587, p\right.$ value $\left.=0.036\right)$, and moderate to morbid obesity $\left(\chi^{2}=6.453, p\right.$ value $\left.=0.012\right)$.

According to the logistic regression, women who were aged 35 years and above were twice more likely to have failed LOD than their younger age-group $(\mathrm{OR}=2, \mathrm{Cl}=1.5-45, p$ value $=0.003)$. Women with altered LH/FSH (i.e., ratio > 2.0) were twice less likely to have failed LOD compared to those without altered LH/FSH $(\mathrm{OR}=0.5, \mathrm{Cl}=0.1-0.8, p$ value $=0.004)$. Other predictors of failed LOD were infertility duration of 5 years and above $(\mathrm{OR}=3, \mathrm{Cl}=$ $2.2-6.7, p$ value $=0.005)$, obesity $(\mathrm{OR}=4, \mathrm{Cl}=2-6, p$ value $=0.002)$ (Tables 1 to 4 ).

\begin{tabular}{|c|c|c|}
\hline Variables & Frequency $(n=43)$ & Percentage \\
\hline \multicolumn{3}{|l|}{ Age (years) } \\
\hline $21-25$ & 18 & 41.9 \\
\hline $26-30$ & 8 & 18.6 \\
\hline $31-35$ & 6 & 14.0 \\
\hline$>35$ & 11 & 25.5 \\
\hline Range $21-43$ & Mean $=29.5 \pm 4.8$ & \\
\hline \multicolumn{3}{|l|}{ Type of infertility } \\
\hline Primary & 30 & 69.8 \\
\hline Secondary & 13 & 30.2 \\
\hline \multicolumn{3}{|c|}{ Infertility duration (years) } \\
\hline $1-5$ & 22 & 51.2 \\
\hline $6-10$ & 14 & 32.6 \\
\hline$>10$ & 7 & 16.2 \\
\hline Range 1-18 & Mean $=6.0 \pm 3.7$ & \\
\hline \multicolumn{3}{|l|}{ Social class } \\
\hline Upper & 7 & 16.2 \\
\hline Middle & 8 & 18.6 \\
\hline Low & 28 & 65.2 \\
\hline \multicolumn{3}{|l|}{ Irregular cycles } \\
\hline Yes & 40 & 93 \\
\hline No & 3 & 7 \\
\hline \multicolumn{3}{|c|}{ Altered $\mathrm{LH} / \mathrm{FSH}$ ratio $(\geq 2.0)$} \\
\hline Yes & 28 & 65.2 \\
\hline \multirow[t]{2}{*}{ No } & 15 & 34.8 \\
\hline & Mean $=3.9( \pm 1.8)$ & \\
\hline \multicolumn{3}{|l|}{$\mathrm{BMI}\left(\mathrm{kg} / \mathrm{M}^{2}\right)$} \\
\hline$<25$ & 2 & 4.7 \\
\hline $25-29$ & 18 & 41.9 \\
\hline$\geq 30$ & 23 & 53.4 \\
\hline Range $24.3-39$ & Mean $=30.3(3 \pm 6.5$ & \\
\hline
\end{tabular}

Table 2: Outcome variables studied in the patients

\begin{tabular}{lcc}
\hline Outcome variables & Frequency & Percentage \\
\hline Resumption of spontaneous regular & menses/ovulation \\
Yes & 30 & 76.9 \\
No & 9 & 23.1 \\
Total & 39 & 100.0 \\
Clinical pregnancy & & \\
Yes & 23 & 59.0 \\
No & 16 & 41.0 \\
Total & 39 & 100.0 \\
Conception after drilling (in months) $n=23$ & \\
$1-3$ & 4 & 10.3 \\
$4-6$ & 12 & 52.2 \\
$\geq 7$ & 7 & 37.5 \\
Mean time of conception post-drilling 4.8 & 1.6 months \\
Pregnancy outcome & & \\
Miscarriage & 4 & 10.3 \\
Live birth & 19 & 48.7 \\
Total & 23 & 59.0 \\
\hline
\end{tabular}


Table 3: Association between baseline characteristics of the patient and failed LOD

\begin{tabular}{|c|c|c|c|c|c|}
\hline \multirow[b]{2}{*}{ Variable } & \multicolumn{2}{|c|}{ Failed LOD } & \multirow[b]{2}{*}{ Total } & \multirow[b]{2}{*}{$x^{2}$} & \multirow[b]{2}{*}{$p$ value } \\
\hline & Yes, $n(\%)$ & No, $n(\%)$ & & & \\
\hline \multicolumn{6}{|l|}{ Age (years) } \\
\hline$\leq 35$ & $3(10.3)$ & $26(89.7)$ & $29(100)$ & 10.063 & $p=0.004^{*}$ \\
\hline$>35$ & $6(60)$ & $4(40)$ & $10(100)$ & & \\
\hline \multicolumn{6}{|c|}{ Types of infertility } \\
\hline Primary & $6(22.2)$ & $21(77.8)$ & $27(100)$ & 0.035 & $p=0.576^{*}$ \\
\hline Secondary & $3(25)$ & $9(75)$ & $12(100)$ & & \\
\hline \multicolumn{6}{|c|}{ Duration of infertility } \\
\hline$\leq 5$ years & $2(9.5)$ & $19(90.5)$ & $21(100)$ & 4.587 & $p=0.036^{*}$ \\
\hline$>5$ years & $7(38.9)$ & $11(61.1)$ & $18(100)$ & & \\
\hline \multicolumn{6}{|c|}{ Altered $\mathrm{LH} / \mathrm{FSH}$ ratio $(\geq 2.0)$} \\
\hline Yes & $3(11.5)$ & $23(88.5)$ & $26(100)$ & 5.700 & $p=0.024^{*}$ \\
\hline No & $6(46.2)$ & $7(53.8)$ & $13(100)$ & & \\
\hline \multicolumn{6}{|l|}{ BMI $\left(\mathrm{Kg} / \mathrm{M}^{2}\right)$} \\
\hline$<30$ & $1(5.3)$ & $18(94.7)$ & $19(100)$ & 6.453 & $p=0.012^{*}$ \\
\hline$\geq 30$ & $8(40)$ & $12(60)$ & $20(100)$ & & \\
\hline
\end{tabular}

${ }^{*} p$ values are Fisher's exact test

Table 4: logistic Regression showing predictors of failed LOD among the patients

\begin{tabular}{|c|c|c|c|}
\hline \multirow[b]{3}{*}{ Variables } & \multicolumn{3}{|c|}{ Failed LOD } \\
\hline & \multicolumn{3}{|c|}{$N=9(\%)$} \\
\hline & $O R$ & $95 \% \mathrm{Cl}$ & $p$ \\
\hline \multicolumn{4}{|l|}{ Age (years) } \\
\hline \multicolumn{4}{|l|}{$(\operatorname{Ref}=\leq 35)$} \\
\hline$>35$ & 2 & $1.5-4.5$ & 0.003 \\
\hline \multicolumn{4}{|c|}{ Duration of infertility } \\
\hline \multicolumn{4}{|c|}{ (Ref $=\leq 5$ years $)$} \\
\hline$>5$ years & 3 & $2.2-6.7$ & 0.005 \\
\hline \multicolumn{4}{|c|}{ Type of infertility } \\
\hline \multicolumn{4}{|c|}{$($ Ref $=$ primary $)$} \\
\hline Secondary & 2 & $0.5-3.5$ & 0.35 \\
\hline \multicolumn{4}{|c|}{ Altered LH/FSH (>2.0) } \\
\hline \multicolumn{4}{|l|}{ (Ref = yes) } \\
\hline No & 0.5 & $0.1-0.8$ & 0.004 \\
\hline \multicolumn{4}{|l|}{ BMI $\left(\mathrm{kg} / \mathrm{M}^{2}\right)$} \\
\hline \multicolumn{4}{|l|}{$(\operatorname{Ref}=<30)$} \\
\hline$\geq 30$ & 4 & $2-6$ & 0.002 \\
\hline
\end{tabular}

\section{Discussion}

In this study, the prevalence rate of PCOS was $18.6 \%$. This finding is similar to the prevalence rate of $18.1 \%$ reported in Enugu by Ugwu et al. ${ }^{1}$ but lower than the $32 \%$ and $31 \%$ reported by Pembe et al. in Tanzania in $2009^{19}$ and Omokanye et al. ${ }^{4}$ in Ilorin, NorthCentral Nigeria respectively. A lower prevalence rate of $12.2 \%$ was reported by Ogueh et al., ${ }^{20}$ respectively. The variation in prevalence rates may be due to differences in the prevalence rates of PCOS's genetic and environmental determinants in the various populations or discrepancies in the study populations.

The majority of the women in this study were within the age-group 21-35 years, with a mean age of 29.5 years. This result is similar to the findings in Enugu, Nigeria, with a mean age of
30 years $^{1}$ although slightly higher than the mean age of 27 years recorded in Nnewi, Nigeria. ${ }^{20}$ However, this is not surprising as the PCOS is a complex endocrine disorder affecting women in their reproductive years. ${ }^{1,20}$

A common feature of PCOS is menstrual cycle disturbance. A previous study reported that about $87 \%$ of participants in an earlier study had oligomenorrhea. Approximately $26 \%$ of those with secondary amenorrhea who presented in a gynecological clinic in that study have polycystic ovaries on ultrasound. ${ }^{21}$ In our study, we recorded irregular cycles in $93 \%$ of the patients. Elevated serum LH concentrations, seen in $40-60 \%$ of the PCOS patients led to a reduced chance of conception and increased miscarriage risk. ${ }^{22}$ Lean patients with PCOS have elevated LH levels. While a high $\mathrm{LH}-\mathrm{FSH}$ ratio is pathognomonic of the disease, it is not required to diagnose PCOS. Reports have also suggested that PCO patients may secrete LH isoforms with high biological activity. Research has observed that patients with high baseline LH levels have a better prognosis. ${ }^{22}$ Our study shows an increase in the LH-FSH ratio in $65.2 \%$ of patients with an average $\mathrm{LH}-\mathrm{FSH}$ ratio of $2.1( \pm 1.8)$. This finding compares favorably to the discovery of Mandeep et al., ${ }^{14}$ where $62 \%$ of the respondents had LH-FSH ratio $>2$.

For this study, we chose the number of punctures empirically based on the size of the ovary. Between 4 and 10 diathermy punctures (each $3 \mathrm{~mm}$ in diameter, 2-4 $\mathrm{mm}$ depth) per ovary was applied using a power setting of $40 \mathrm{~W}$ for 4 seconds delivering between $640 \mathrm{~J}$ and $960 \mathrm{~J}$ of energy per ovary. "About $640 \mathrm{~J}$ is the lowest effective dose recommended". ${ }^{23}$ However, the clinical response depends on the dose with higher ovulation and pregnancy rates observed by increasing thermal energy quantities up to $600 \mathrm{~J} /$ ovary, irrespective of ovarian volume. ${ }^{24}$ Conversely, adjusting thermal dose based on ovarian volume $\left(60 \mathrm{~J} / \mathrm{cm}^{3}\right)$ has better reproductive outcomes with similar postoperative adhesion rates than a fixed dose of $600 \mathrm{~J} / \mathrm{ovary} .^{25}$

We performed bilateral ovarian drilling for the patients in this study. Despite lack of convincing evidence and a significant reduction in operative time, most gynecologists still perform bilateral rather than unilateral drilling. ${ }^{26-28}$ 
We used a monopolar diathermy needle (Tritome) in this study for LOD. Researchers proposed different modifications of the classic needle electrode techniques. These modifications include using the bipolar needle, laparoscopic ovarian multi-needle intervention, LOD using a monopolar hook electrode, LOD using the harmonic scalpel, and office micro laparoscopic ovarian drilling. ${ }^{29-32}$ Researchers also developed various transvaginal methods such as transvaginal hydrolaparoscopy (fertiloscopy) and transvaginal sonographyguided ovarian interstitial laser treatment. ${ }^{33-35}$ However, more extensive prospective studies are needed to validate use, safety, efficacy, and long-term effects of alternate techniques.

The exact mechanism of LOD is unknown. The destruction of androgen-producing stroma was the proposed beneficial effect. There is a reduction in the circulating and intra-ovarian levels. Previous data showed that LOD also has a modulating effect on the pituitary-ovarian axis. ${ }^{23}$ The resumption of regular cycles and ovulation is due to the rapid endocrine changes that may last for months to years. ${ }^{24}$ The assessment of tubal patency and diagnosis of other pelvic pathologies, done simultaneously, is an additional advantage of LOD. Previous evidence showed that the sensitivity of the ovaries to ovulation induction agents increases after the procedure. Other benefits of LOD include more orderly growth of follicles, reduced chances in cycle cancellation, and decreased risk of OHSS.

An environment with low androgen, $\mathrm{AMH}, \mathrm{LH}$ levels, and relatively fewer follicles are more favorable for proper follicular growth.

The majority $(76.9 \%)$ of the patients resumed menses with spontaneous ovulation. This finding is similar to $84.2 \%$ and $77.7 \%$ reported in $\operatorname{Japan}^{25}$ and Poland, ${ }^{27}$ respectively, but lower than finding from Ilorin ${ }^{4}$ South-Western Nigeria. The higher ovulation rate in the study done in llorin may be because the patients were started on clomiphene citrate on the resumption of menses following LOD.

The clinical pregnancy rate of $59 \%$ falls within the range of $43-84 \%$ reported by some studies ${ }^{14,15,24,25}$ although slightly higher than Ilorin's rate. The difference may be due to the effects of other infertility factors not excluded in the llorin study.

Previous reports have shown that PCOS patients have higher miscarriage rates as compared to the general population. Elevated $\mathrm{LH}$ is the main culprit. Other significant contributors to the increased miscarriage rates in PCOS patients include hyperinsulinemia and obesity. ${ }^{28}$ LOD reduces LH levels as well as the risk of miscarriage. Previous data reported a miscarriage rate of $14 \%$ after LOD than the 30 to $40 \%$ expected rate in PCOS patients. ${ }^{24}$ The miscarriage rate in this study was $10.3 \%$. This result is comparable to $14 \%$ reported by Ikechebelu et al. ${ }^{13}$ The live birth rate in this study was $48.7 \%$. This discovery is similar to the finding of Mandeep et al.

There was no record of multiple pregnancies or OHSS in the study participants, which further established the safety of LOD over gonadotropins.

Predictors of failed LOD in this study were aged above 35 years, duration of infertility above 5 years, and moderate to morbid obesity. These are similar to the findings of other studies. 13,14

To our knowledge, this study is one of the very few studies that assessed prognostic factors for an ovarian response following laparoscopic electrocautery using a logistic regression model with prospective data collection in West Africa. Other studies done so far are either cross-sectional or retrospective, while few other prospective studies did not look out for failed LOD predictors. LOD had a higher successful pregnancy outcome in patients with normal
BMI and BMI of $<30 \mathrm{~kg} / \mathrm{m}^{2}$ than those with a BMI of $>30 \mathrm{~kg} / \mathrm{m}^{2}$. This finding is similar to that observed in a cross-sectional done by Omokanye et al. ${ }^{26}$ hence, alternative treatment methods may need to be used for this group of patients, such as weight reduction, metformin treatment, gonadotropin therapy, or IVF to achieve conception.

The infertility duration of 5 years and below had the most substantial impact as a predictor of success. This result is in agreement with the previous study. ${ }^{26} \mathrm{~A}$ possible explanation for the role of infertility duration may be the emergence of other subfertility factors as the duration of infertility increases. ${ }^{26}$

One of LOD's main shortcomings is iatrogenic adhesions due to bleeding from the ovarian surface or premature contact between the ovary and the bowel after cauterization. Adhesion rates ranged from 0 to $100 \%,{ }^{12,33,34,36,37}$ involving higher risks with laser. ${ }^{36,37}$ This higher figure is probably due to less thermal penetration ( $2-4 \mathrm{~mm}$ ) by the cone-shaped laser drilling lesions compared to cylindershaped lesions $(8 \mathrm{~mm}$ ) of monopolar electrocoagulation. Most studies reported mild-to-moderate adhesions, which do not seem to affect pregnancy rates after LOD. Adhesion prevention strategies such as liberal peritoneal lavage, adhesion barriers like intercede, ${ }^{38}$ and adhesiolysis performance at early second-look laparoscopy ${ }^{39}$ are not effective in preventing de novo adhesions or in improving pregnancy rates. ${ }^{38}$ We raised the ovaries before applying energy in this study and saline washed after the procedure to decrease the temperature, reducing the risk of injury.

Another potential risk is premature ovarian failure, significantly if the ovarian blood supply is damaged inadvertently or if the surgeon makes a large number of punctures, leading to excessive destruction of ovarian follicular pool or production of anti-ovarian antibodies. ${ }^{36}$ When applied correctly, as done in this study, the coagulation puncture does not appear to compromise the ovarian reserve. A prospective comparative study found that the extent of ovarian tissue damage was limited, ranging from $0.4 \%$ after four to $1 \%$ after eight coagulation punctures, each of $40 \mathrm{~W}$ for 5 seconds. ${ }^{37}$ We can interpret changes in ovarian reserve markers as normalization of ovarian function rather than reducing ovarian reserve. Surgeons should not do coagulation within $8-10 \mathrm{~mm}$ of the ovarian hilum. ${ }^{40}$ The use of unilateral drilling, ${ }^{28,41}$ use of the harmonic scalpel, ${ }^{32,42}$ and use of bipolar energy ${ }^{15,43}$ are associated with a less risk of adhesions and Decreased Ovarian Reserve (DOR) ${ }^{44}$ but with equivalent reproductive outcomes with bilateral drilling using monopolar diathermy.

Readers should interpret the findings from this study in light of some limitations. First, the small sample size makes it difficult for the results to be generalized. Also, the limited laboratory resources at the study center made it difficult to assay some hormones that could have added to this study's quality.

Nevertheless, our findings have significant implications for Nigeria's reproductive interventions since anovulatory infertility is a significant public health issue in our area and globally.

\section{Conclusion}

Laparoscopic ovarian drilling is a feasible, safe, and effective first-line treatment option in patients with clomiphene-resistant PCOS in sub-Saharan Africa. Emphasis should be on weight reduction with early recourse to LOD in managing patients with clomiphene-resistant PCOS. Early recourse will reduce the time to achieve pregnancy and the need for ovulation induction using gonadotropins. 


\section{ACKnOWLedgments}

We are using this opportunity to acknowledge the useful contribution from Dr Olusegun Badejoko of the Department of Obstetrics, Gynecology, and Perinatology, Obafemi Awolowo University Teaching Hospitals Complex, Ile-Ife, Osun State, who trained us in laparoscopy and assisted during the procedure.

\section{References}

1. Ugwu GO, lyoke CA, Onah HE, et al. Prevalence, presentation, and management of polycystic ovary syndrome in Enugu, Southeast Nigeria. Niger J Med 2013;22:313-316.

2. Lucidi RS. Polycystic Ovarian Syndrome. Available from: http://www. emedicine.medscaperre.com/article/25680-overview. [Last accessed on 2014Apr 06].

3. Lavie O. Benign disorders of the ovaries and oviducts Alan HD, Lauren $\mathrm{N}$, Ashley SR, ed. Current Obstetrics and Gynecologic Diagnosis and Treatment. 11th ed., New York: Lange Medical Publication; 2013. pp. 661-670.

4. Omokanye LO, Olatinwo AWO, Durowade KA, et al. A review of pregnancy outcome following laparoscopic ovarian drilling for infertile women with the clomiphene-resistant polycystic ovarian syndrome at a public health facility in Ilorin, Nigeria. Trop J Obstet Gynaecol 2014;31(2):74-81.

5. Adam HB, Edmonds DK. Polycystic ovary syndrome and secondary amenorrhea. 7th ed., UK: John Wiley \& Sons, Inc; 2007.

6. Seli E, Duleba AJ. Optimizing ovulation induction in women with polycystic ovary syndrome. Curr Opin Obstet Gynecol 2002;14(3): 245-254. DOI: 10.1097/00001703-200206000-00002.

7. Goodarzi MO, Azziz R. Diagnosis, epidemiology and genetics of the polycystic ovarian syndrome. Best Pract Res Clin Endocrinol Metab 2006;20(2):193-205. DOI: 10.1016/j.beem.2006.02.005.

8. Azziz R, Carmina E, Dewailly D, et al. The androgen excess and PCOS society criteria for the polycystic ovary syndrome: the complete task force report. Fertil Steril 2009;91(2):456-488. DOI: 10.1016/j. fertnstert.2008.06.035.

9. Balen AH, Laven JSE, Tan SL, et al. Ultrasound assessment of the polycystic ovary: international consensus definitions. Human Reprod Update 2003;9(6):505-514. DOI: 10.1093/humupd/ dmg044.

10. Glintborg $D$, Andersen M. An update on the pathogenesis, inflammation, and metabolism in hirsutism and polycystic ovary syndrome. Gynecol Endocrinol 2010;26(4):281-296. DOI: 10.3109/09513590903247873.

11. Klufio CA. Polycystic ovary syndrome Kwakwume EY, Emuveyan EE, ed. Comprehensive Gynaecology in the Tropics. 1st ed., Accra: Graphic Packaging Limited; 2005. pp. 325-332.

12. Boyle J. Infertility in women with polycystic ovary syndrome and the role of metformin in the management. Expert Rev Obstet Gynecol 2013;8(6):581-586. DOI: 10.1586/17474108.2013.842689.

13. Ikechebelu JI, Mbamara SU, Okeke CAF. Pregnancy following laparoscopic ovarian drilling for the clomiphene-resistant polycystic ovarian syndrome. Niger J Clin Pract 2010;13(2):235-237.

14. Mandeep K, Gautham P, Manishi M, et al. Outcome of laparoscopic ovarian drilling in patients with clomiphene citrate resistant polycystic ovarian syndrome in tertiary care center. Int J Infert Fet Med 2013;4:39-44.

15. Gjonnaess H. Polycystic ovarian syndrome treated by ovarian electrocautery through the laparoscope. Fertil Steril 1984;49(1):956960. DOI: 10.1016/S0015-0282(16)47534-5.

16. Greenbalt $E$, Casper RF. Endocrine changes after laparoscopic ovarian cautery in polycystic ovarian syndrome. Am J Obsteand Gynae 1987;156(2):279-285. DOI: 10.1016/0002-9378(87)90268-7.

17. Kovacs $\mathrm{G}$, Buckler $\mathrm{H}$, Bangah $\mathrm{M}$, et al. Treatment of anovulation due to polycystic ovarian syndrome by laparoscopic ovarian electrocautery. British J Obstet and Gynae 1991;98(1):30-35. DOI: 10.1111/j.14710528.1991.tb10307.x.
18. Olusanya O, Okpere E, Ezimokhai M. The importance of social class involuntary fertility control in a developing country. West Afri Med J 1985;4:205-211.

19. Pembe AB, Abeid MS. Polycystic ovaries, and associated clinical and biochemical features among women with infertility in a tertiary hospital in Tanzania. Tanzan J Health Res 2009;11:175-178.

20. Ogueh $\mathrm{O}$, Zini M, Williams S, et al. The prevalence of polycystic ovary morphology among women attending a new teaching hospital in southern Nigeria. Afr J Reprod Health 2014;18:160-163.

21. Adams J, Polson DW, Franks S. Prevalence of polycystic ovaries in women with anovulation and idiopathic hirsutism. Br Med J 1986;293(6543):355-359. DOI: 10.1136/bmj.293.6543.355.

22. Homburg R. Pregnancy complications in PCOS. Best Pract Res Clin Endocrinol Metab 2006;20(2):281-292. DOI: 10.1016/j. beem.2006.03.009.

23. Armar NA, McGarrigle HHG, Honour J, et al. Laparoscopic ovarian diathermy in the management of anovulatory infertility in women with polycystic ovaries: Endocrine changes and clinical outcome. Fertil Steril 1990;53(1):45-49. DOI: 10.1016/S0015-0282(16) 53214-2.

24. Amer SA, Li TC, Cooke ID. A prospective dose-finding study of the amount of thermal energy required for laparoscopic ovarian diathermy. Hum Reprod 2003;18(8):1693-1698. DOI: 10.1093/humrep/ deg307.

25. Zakherah MS, Kamal MM, Hamed HO. Laparoscopic ovarian drilling in polycystic ovary syndrome: efficacy of adjusted thermal dose based on ovarian volume. Fertil Steril 2011;95(3):1115-1118. DOI: 10.1016/j. fertnstert.2010.10.037.

26. Omokanye LO, Olatinwo AO, Panti A, et al. Clomiphene resistant polycystic ovarian syndrome: analysis of outcomes following laparoscopic ovarian drilling in infertile women in Ilorin, Northcentral, Nigeria. Ann Trop Med Public Health 2017;10:1292-1298.

27. Youssef $\mathrm{H}$, Atallah MM. Unilateral ovarian drilling in polycystic ovarian syndrome: a prospective randomized study. Reprod Biomed Online 2007;15(4):457-462. DOI: 10.1016/S1472-6483(10)60373-2.

28. Al-Mizyen E, Grudzinskas JG. Unilateral laparoscopic ovarian diathermy in infertile women with clomiphene citrate-resistant polycystic ovary syndrome. Fertil Steril 2007;88(6):1678-1680. DOI: 10.1016/j.fertnstert.2007.01.060.

29. Rossmanith WG, Keckstein J, Spatzler K, et al. The impact of ovarian laser surgery on gonadotropin secretion in women with the polycystic ovarian disease. Clin Endocrinol (Oxf) 1991;34(3):223-230. DOI: 10.1111/j.1365-2265.1991.tb00298.x.

30. Amer SAK, Gopalan V, Li TC, et al. Long-term follow-up of polycystic ovary disease after laparoscopic ovarian drilling: clinical outcome. Hum Reprod 2002;17(8):2035-2042. DOI: 10.1093/humrep/17.8.2035.

31. Kato M, Kikuchi I, Shimaniki H, et al. Efficacy of laparoscopic ovarian drilling for polycystic ovary syndrome resistant to clomiphene citrate. J Obstet Gynaecol Res 2007;33(2):174-180. DOI: 10.1111/j.14470756.2007.00504.x.

32. Marianowski P, Kaminski P, Wielgos $M$, et al. The changes in hormonal serum level and ovulation/pregnancy rates after ovarian electrocautery in micro-laparoscopy and laparoscopy in patients with PCOS. Neuro Endocrinol Lett 2006;27(1-2):214-218.

33. Poujade O, Gervaise A, Faivre E, et al. Surgical management of infertility due to polycystic ovarian syndrome after failed medical management. Eur J Obstet Gynecol Reprod Biol 2011;158(2):242-247. DOI: 10.1016/j.ejogrb.2011.05.007.

34. Fernandez H, Alby JD, Gervaise A, et al. Operative transvaginal hydrolaparoscopy for polycystic treatment ovary syndrome: a new minimally invasive surgery. Fertil Steril 2001;75(3):607-611. DOI: 10.1016/S0015-0282(00)01746-5.

35. Fernandez $\mathrm{H}$, Watrelot $\mathrm{A}$, Alby JD, et al. Fertility after ovarian drilling by transvaginal fertiloscopy for treatment of polycystic ovary syndrome. J Am Assoc Gynecol Laparosc 2004;11(3):374-378. DOI: 10.1016/S1074-3804(05)60054-0.

36. Greenblatt EM, Casper RF. Adhesion formation after laparoscopic ovarian cautery for the polycystic ovarian syndrome: LO ack of 
correlation with pregnancy rate. Fertil Steril 1993;60(5):766-770. DOI: 10.1016/S0015-0282(16)56273-6.

37. Saravelos H, Li TC. Post-operative adhesions after laparoscopic electrosurgical treatment for polycystic ovarian syndrome with the application of Intercede to one ovary: a prospective randomized controlled study. Hum Reprod 1996;11(5):992-997. DOI: 10.1093/ oxfordjournals.humrep.a019337.

38. Gürgan T, Urman B, Aksu T, et al. The effect of short-interval laparoscopic lysis of adhesions on pregnancy rates following $\mathrm{Nd}$-YAG laser photocoagulation of polycystic ovaries. Obstet Gynecol 1992;80:45-47.

39. Naether OG, Fischer R. Adhesion formation after laparoscopic electrocoagulation of the ovarian surface in polycystic ovary patients. Fertil Steril 1993;60(1):95-98. DOI: 10.1016/S0015-0282(16) 56043-9.
40. Mercorio F, Mercorio A, Di Spiezio Sardo A, et al. Evaluation of ovarian adhesion formation after laparoscopic ovarian drilling by second-look mini laparoscopy. Fertil Steril 2008;89(5):1229-1233. DOI: 10.1016/j.fertnstert.2007.05.009.

41. Naether OG. Significant reduction of adnexal adhesions following laparoscopic electrocautery of the ovarian surface (LEOS) by lavage and artificial ascites. Gynaecol Endosc 1995;4:17-19.

42. Dabirashrafi H. Complications of laparoscopic ovarian cauterization. Fertil Steril 1989;52:878-879.

43. El-Sheikhah A, Aboulghar M, Read R, et al. The extent of ovarian damage produced by ovarian cauterization in the human. J Obstet Gynaecol 2004;24(6):664-666. DOI: 10.1080/01443610400007992.

44. Api M. Is ovarian reserve diminished after laparoscopic ovarian drilling? Gynecol Endocrinol 2009;25(3):159-165. DOI: 10.1080/09513590802585605. 